\title{
Ketosis an Old Story Under a New Approach
}

\author{
Guanshi Zhang 1,2,3(1) and Burim N. Ametaj ${ }^{1, * \mathbb{C}}$ \\ 1 Department of Agricultural, Food and Nutritional Science, University of Alberta, Edmonton, \\ AB T6G 2P5, Canada; guanshi@ualberta.ca \\ 2 Center for Renal Precision Medicine, Division of Nephrology, Department of Medicine, \\ The University of Texas Health, San Antonio, TX 78229, USA \\ 3 Audie L. Murphy Memorial VA Hospital, South Texas Veterans Health Care System, San Antonio, \\ TX 78229, USA \\ * Correspondence: burim.ametaj@ualberta.ca; Tel.: +780-492-9841
}

Received: 5 April 2020; Accepted: 8 May 2020; Published: 10 May 2020

\begin{abstract}
Ketosis, characterized by high concentrations of ketone bodies in the blood, urine, and milk, affects a considerable number of cows immediately after calving. Although much is known about ketosis, dairy cows continue to be affected in every herd world-wide. Cows affected by ketosis are treated with palliative treatments after the disease is diagnosed. This is a very expensive approach and costs the dairy industry extra expenses, contributing to lower profitability of dairy herds. In this review article, we summarize the mainstream view on ketosis, classification of ketosis into three types, current diagnostic approaches to ketosis, and the economic impact of ketosis on dairy farms. Additionally, we discuss the most recent applications of the new 'omics' science of metabolomics in studying the etiopathology of ketosis as well as its contribution in identification of novel screening or diagnostic biomarkers of ketosis.
\end{abstract}

Keywords: ketosis; dairy cows; conventional view; immunology; metabolomics

\section{Introduction}

Ketosis refers to a metabolic disease of dairy cows characterized by high ketone bodies [i.e., $\beta$-hydroxybutyrate ( $\beta \mathrm{OHB})$, acetoacetate (AcAc), and acetone (Ac)] in the blood, urine, and milk that occurs in early lactation. The source of ketones might be exogenous (diet) or endogenous (adipose tissue). The current leading hypothesis on the etiology of ketosis is establishment of a state of negative energy balance (NEB) around calving, which triggers mobilization of long-chain fatty acids from adipose tissue that are oxidized in the liver into ketone bodies. More specifically, immediately after calving, there is an imbalance between the energy that enters into the body as feed (dry-matter intake-DMI) and the energy that is released from the body in the form of milk. Because of this imbalance (NEB), the cow enters into a negative energy status that triggers lipolysis of triacylglycerols stored in adipose tissue, releasing large amounts of free or non-esterified fatty acids (NEFAs) into the blood circulation. Usually NEFAs are esterified in the liver and delivered into the systemic circulation with very low-density lipoproteins (VLDL). However, if the amount of NEFAs is in excess of the liver capacity to esterify them, they are incompletely oxidized in hepatocyte mitochondria to ketone bodies. Mobilization of NEFAs is a host response to spare the glucose that is lacking and complement the energy shortage by burning NEFAs into acetyl-CoA and then ketone bodies. Ketone bodies represent a usable form of lipid-derived energy, as they can penetrate the blood brain barrier (BBB) and supply the brain with a source of energy (fatty acids cannot pass the BBB). However, high concentrations of ketone bodies in blood, urine, and milk have been associated with decreased feed intake and increased susceptibility to other periparturient diseases. The main challenge to the NEB hypothesis is that it cannot explain the fact that although all cows go through 
NEB, why only part of the cows in a herd are affected by ketosis and not all of them? In this new era of a systems biology approach to disease, 'omics' approaches are important tools to give new insight into the etiopathology of diseases. More details about the current conventional hypothesis on ketosis and the new knowledge generated by metabolomics and immunology approaches to ketosis will be discussed below.

\section{Ketosis and Its Impact on the Dairy Industry}

\subsection{Conventional View of Ketosis}

Transition dairy cows undergo major physiological changes from late gestation to early lactation. Ketosis is a common metabolic disorder that frequently occurs during the so-called transition period. Ketosis is characterized by increased concentrations of ketone bodies including acetoacetate (AcAc), acetone (Ac), and $\beta \mathrm{OHB}$ in the blood, urine, and milk in early lactation $[1,2]$.

The incidence rate of ketosis has surpassed those of ruminal acidosis and milk fever and has emerged as one of the most important metabolic perturbations of dairy cows in North America since the late 1990s [3]. Indeed, almost $40 \%$ of dairy cows in North America have different degrees of ketosis within a few weeks after calving, with the incidence varying widely between farms and reaching as high as $80 \%$, in some dairy herds [4]. The negative impacts of ketosis may include lowered milk yield, impaired reproductive performance (e.g., infertility), greater risk of other periparturient diseases including displaced abomasum, lameness, mastitis, metritis, and retained placenta, and a greater culling rate [5-8]. The cost of a single case of ketosis has been estimated to be around Canadian (CAD) $\$ 50$ to $\$ 100$ [4].

Although ketosis has been extensively reviewed over time $[4,7,9]$, the precise causes and pathobiology of ketosis remain unknown. Dairy cows generally experience a state of NEB around calving characterized by excessive mobilization of free fatty acids from adipose tissue due to low dry matter intake (DMI) [10]. Fatty acids follow four pathways in the liver: (1) complete oxidation via the tricarboxylic acid cycle to generate $\mathrm{H}_{2} \mathrm{O}, \mathrm{CO}_{2}$, and energy; (2) incomplete oxidation resulting in the release of ketone bodies and less energy; (3) exported out of the liver as part of VLDL; and (4) esterification of non-esterified fatty acids (NEFA) to triacylglycerols (TAG) and accumulation within the hepatocytes [11,12].

The exact pathobiology of hyperketonemia is not fully understood [10]. The most dominant hypothesis is that there is an energy (i.e., glucose) deficit immediately postpartum. Apparently, the gluconeogenic ability of the liver cannot meet the demands of the postpartum cow for glucose, because $60 \%$ to $85 \%$ of the available glucose is utilized by the mammary gland for milk synthesis [13]. Hypoglycemia may result from either inadequate gluconeogenic precursors or a limited rate of gluconeogenesis $[9,13]$. Low concentrations of blood glucose are associated with hypoinsulinemia, which subsequently triggers mobilization of fatty acids from adipose tissue, thereby increasing ketone body formation. The process of hepatic ketogenesis and ketone body utilization in extrahepatic organs is illustrated in Figure 1. In the liver, fatty acids are either oxidized to carbon dioxide and ketone bodies or re-esterified into triglycerides (TG) for storage and incorporation into very low-density lipoproteins (VLDL) [14]. Excess accumulation of TG leads to fatty liver, which further impairs liver functions, limiting the process of gluconeogenesis. 


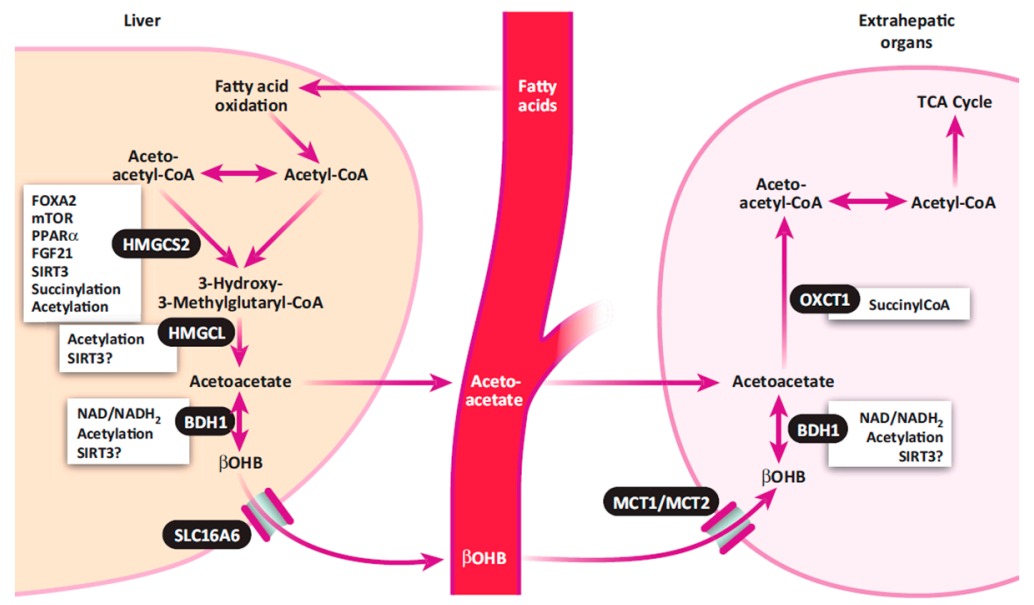

Figure 1. Outline of hepatic ketogenesis and ketone body utilization in extrahepatic organs. Abbreviations: BDH1, $\beta$-hydroxybutyrate dehydrogenase; $\beta \mathrm{OHB}, \beta$-hydroxybutyrate; FGF21, fibroblast growth factor 21; FOXA2, forkhead box A2; HMGCS2, 3-hydroxy-3-methylglutaryl (HMG)-CoA synthase 2; HMGCL, HMG-CoA lyase; MCT1/2, monocarboxylic acid transporters 1/2; mTOR, mechanistic target of rapamycin; OXCT1, succinyl-CoA:3-ketoacid coenzyme A transferase; $\operatorname{PPAR} \alpha$, peroxisome proliferator activated receptor $\alpha$; SIRT3, sirtuin 3; SLC16A6, solute carrier family 16 (monocarboxylic acid transporter), member 6; TCA cycle, tricarboxylic acid cycle (Adapted from [15]).

It was reported that fat accumulation in the liver during the dry-off period or even during the previous lactation period may contribute to the development of ketosis [16,17]. However, most investigations have been focused on the concentrations of ketone bodies in the body fluids postpartum for evaluating ketosis, although a few studies have attempted to assess the association between ketones or other variables in body fluids (i.e., blood and urine) prepartum and ketosis diagnosed after parturition. It is obvious that more research is warranted to better understand the pathobiology of ketosis and to determine more details about the metabolic alterations in the blood and urine during the prepartum period.

\subsection{Classification of Ketosis}

Several schemes for classifying ketosis have been reported and two different approaches are commonly used by various researchers. The first categorization is based on concentrations of $\beta \mathrm{OHB}$ in the blood and the lack or presence of clinical signs of disease. Accordingly, ketosis is classified into two forms including subclinical ketosis (SCK) and clinical ketosis (CK). SCK is defined as an increase of ketone bodies in the blood, urine, or milk, in absence of obvious clinical signs of disease. Cow maintains the appetite and there is no decrease in DMI. Concentrations of $\beta O H B$ in the serum between 1200 to $1400 \mu \mathrm{mol} / \mathrm{L}$ are generally used for diagnosis of SCK [18]. CK is characterized by hyperketonemia, hypoglycemia, and the presence of clinical symptoms including lower appetite, loss of body weight, decreased milk production, and dry manure [19]. The clinical form of ketosis is usually recognized at greater concentrations of BHBA in the blood ranging between 2600 to $3000 \mu \mathrm{mol} / \mathrm{L}[3,4]$.

The second classification scheme categorizes ketosis into three general types including type I ketosis, type II ketosis, and butyric acid silage ketosis based on the etiology and timing of hyperketonemia $[3,10,20]$. Type I, or primary ketosis is the classic form of ketosis that occurs between 3 and 6 weeks postpartum when milk energy outflow reaches its peak [20]. It is defined as type I ketosis because it is aligned with type I diabetes mellitus in humans. Cows with type I ketosis experience hypoinsulinemia at the time of diagnosis of hyperketonemia because of chronic hypoglycemia due to a shortage of glucose precursors for milk production. In this case, glucose precursors are absorbed from the diet (mostly propionate) or from muscle proteins in the form of amino acids (AAs, i.e., gluconeogenesis). However, the capacity of the gluconeogenic process is limited due to host 
protection of muscle proteins. On the other hand, lipolysis and ketogenesis are enhanced and fatty acids and ketone bodies are utilized to spare glucose and meet energy requirements [20].

Type II, or secondary ketosis usually occurs immediately after parturition and is concurrent with other diseases such as fatty liver [20]. This form of ketosis is named as type II ketosis based on its human metabolic counterpart-type II diabetes mellitus. Cows with type II ketosis have high concentrations of both blood insulin and glucose at the diagnosis of hyperketonemia [20]. Insulin resistance may also exist during type II ketosis [3]. Obesity and overfeeding during the dry period are critical for the development of this type of ketosis. Mobilization of body fat from adipose tissues and accumulation of triglycerides (TG) may occur prior to or at parturition [3]. Excessive accumulation of TG in the liver not only impairs gluconeogenesis, but also suppresses immune functions of hepatocytes.

Ketosis related to consuming of silage enriched with butyric acid is the third type of ketosis under the second categorization scheme. This type of ketosis has been attributed to intake of feed high in ketogenic precursors (i.e., butyric acid) [21]. The reasons for accumulation of butyric acid in the silage are related to, for example, preparation of silage with hay that contains low water-soluble carbohydrates or silage that is chopped too wet, favoring growth of bacteria from Clostridium sp. [3]. Some carbohydrates in the silage are fermented into butyric acid rather than the preferred lactic acid. Cows develop butyric acid silage ketosis when they ingest large quantities of silages that have undergone clostridial fermentation. However, whether or not a cow develops dietary butyric acid ketosis also depends on the amount of silage consumed and the presence of other risk factors (e.g., early lactation, ruminal acidosis, high milk production, low dietary energy, and high dietary protein) for ketosis [3].

\subsection{Impact of Ketosis on Dairy Cows and the Dairy Industry}

Numerous investigators have demonstrated detrimental effects of ketosis on a cow's health, reproductive performance, milk production, milk composition, and the dairy industry profitability $[5-7,9,22,23]$. In regards to the association between ketosis and subsequent disease occurrence, most studies have been focused on SCK due to its widespread prevalence. Cows with SCK have been reported to be at a greater risk for disorders like displaced abomasum (DA), metritis, endometritis, mastitis, lameness, retained placenta, cystic ovarian disease, impaired fertility, reduced reproductive efficiency, and impaired immune functions [5-8,18,24,25]. The relationship between CK and other periparturient diseases was also reported previously. Ketosis and associated periparturient diseases may increase the likelihood for early culling of cows from the herd during early lactation.

Deleterious effects of ketosis on milk production are well documented. Dohoo and Martin [26] demonstrated that ketotic cows had 1.0 to $1.4 \mathrm{~kg}$ (4.4\% to $6.6 \%)$ lower daily milk yield compared with non-ketotic cows. Findings from another study were very similar, which estimated milk production loss in cows with ketosis at approximately 1 to $2 \mathrm{~kg} / \mathrm{d}$ [5]. In addition, McArt et al. [25] reported that each additional $0.1 \mathrm{mmol} / \mathrm{L}$ increase in the serum $\beta \mathrm{OHB}$ (beyond $1.2 \mathrm{mmol} / \mathrm{L}$ ) at the first diagnosis of SCK is associated with $0.5 \mathrm{~kg} / \mathrm{d}$ more milk loss for the first 30 days in milk (DIM). Milk loss due to hyperketonemia or ketosis consequently lowers the economic profitability of the entire dairy industry. No explanations as to how ketonemia affects milk production have been given by researchers involved in those studies.

The effect of ketosis on milk composition has also been reported previously. For example, Kauppinen [27] reported that cows affected by SCK or CK have greater average annual milk fat yield compared with healthy cows. Another study by Miettinen [28] demonstrated that milk fat percent was increased in cows with SCK. Moreover, milk protein percentage lowered in SCK cows [29]. More research is warranted to identify other milk components affected or to assess the overall quality of milk produced by ketotic cows.

The cost of a single case of SCK has been estimated to be between CAD $\$ 50$ to $\$ 100$ [4]. A similar estimation was also reported by Geishauser et al. [30], which indicated the cost of SCK at CAD \$78 per 
case. The overall cost of ketosis in a dairy herd can be estimated based on the reported incidence of SCK at about $26.4 \%$ to $55.7 \%$ [31] and that of CK between $2 \%$ to $15 \%$ in the first month of lactation [19]. The total ketosis (both CK and SCK) cost was estimated at US \$55.19 to \$123.94 per case [32]. Due to the high incidence rate of ketosis, even a moderate cost per case can result in big losses to the dairy industry.

\section{Current Diagnostic Approaches and Biomarkers for Ketosis}

\subsection{Ketone Bodies in the Blood, Urine, and Milk}

Concentrations of ketone bodies in the blood, urine, and milk have been used for diagnosis of ketosis in dairy cows for many years. Concentrations of $\beta \mathrm{OHB}$ in the blood have been used as the "gold standard" test for ketosis, because $\beta \mathrm{OHB}$ is the predominant ketone body in ruminants, and it is more stable than Ac and AcAc [33]. The most commonly used cut-off value for SCK is $\geq 1400 \mu \mathrm{mol} / \mathrm{L}$ of blood BHBA, while the CK is generally diagnosed by much greater levels of blood $\mathrm{BHBA} \geq 3000 \mu \mathrm{mol} / \mathrm{L}$ [1]. There are no special sampling requirements for blood samples. However, a blood $\beta \mathrm{OHB}$ test should not be performed on blood samples collected from the mammary vein. It was reported that the concentration of $\beta \mathrm{OHB}$ in mammary vein blood is lower because the mammary gland tends to extract $\beta \mathrm{OHB}$ and releases AcAc [34].

Various approaches for diagnosing ketosis based on blood metabolites including $\beta \mathrm{OHB}$ have been reviewed by several authors $[1,35]$. Quantification of serum $\beta O H B$ can be performed using a colorimetric method by a commercial kit and detected by a microplate reader [36]. Other methods including fluorometric determination, gas chromatography-mass spectrometry (GC-MS), and nuclear magnetic resonance (NMR) spectroscopy have also been used to test blood levels of $\beta \mathrm{OHB}$ and Ac $[37,38]$.

Laboratory based tests of milk variables for diagnosis of ketosis have been widely used by researchers. Concentrations of milk $\beta \mathrm{OHB}$ and Ac were measured by Fourier transform infrared spectrometry to detect SCK $[39,40]$. Besides ketone bodies, other milk components have been also used for detection of SCK in dairy cows. The ratio of milk fat percentage to milk protein percentage was used as a tool to evaluate the prevalence of SCK [41,42]. Milk fat/protein (F/P) ratios greater than 1.5 suggests that the cow is affected by SCK [43]. In a study conducted by van Haelst et al. (2008), long-chain fatty acids (e.g., C18:1 cis-9) in milk fat were elevated in cows with SCK during the first nine weeks of lactation.

\subsection{Cow-side Tests for Ketosis}

A variety of validated and practical tools for cow-side tests have been developed for detection of ketosis in dairy herds. Cow-side tests have several advantages including lower cost, immediate results, and less labor, when compared to laboratory analysis. All three main body fluids (i.e., blood, urine, and milk) are feasible for rapid cow-side ketosis tests. Hand-held biosensor for measuring blood ketones (i.e., Precision $\mathrm{X} \operatorname{tra}^{\mathrm{TM}}$ meter ${ }^{\circledR}$ ) is widely used for cow-side blood $\beta \mathrm{OHB}$ test for diagnosis of ketosis in postpartum dairy cows [44].

Urine, as an easily accessible body fluid, can be used for evaluation of ketosis by a cow-side test. The most widely used cow-side urine test for monitoring of ketosis is a semi-quantitative dipstick (Ketostix ${ }^{\circledR}$ urine strip; Bayer Corp. Diagnostics Division, Elkhart, IN, USA) that measures AcAc $[1,3]$. Nitroprusside tablets (Acetest ${ }^{\circledR}$; Bayer Corp. Diagnostics Division, Elkhart, IN, USA) were reported as an approach for quantitative evaluation of urine AcAc for cow-side diagnosis of ketosis [45].

Cow-side milk tests for ketosis have a considerable advantage over both blood and urine tests for ease of milk collection and for assurance that all cows in the herd can be tested at the time of milking. The milk $\beta \mathrm{OHB}$ test strip (also known as KetoTest ${ }^{\circledR}$, Ketolac ${ }^{\circledR} \beta \mathrm{OHB}$, and Sanketopaper ${ }^{\circledR}$ in different countries) is the most promising cow-side milk test for ketosis [1,35]. Milk AcAc can be qualitatively measured by Nitroprusside powders (Utrecht powder, KetoCheck ${ }^{\circledR}$ powder, Saint Joseph, MO, USA) [1]. A study conducted by Geishauser et al. [46] reported that milk AcAc could be measured 
semi-quantitatively by Pink test liquid. A dipstick designed for the measurement of milk $\beta \mathrm{OHB}$ also has been utilized for evaluating urine $\beta O H B$ [47]. The limitations of milk cow-side tests are that generally they are not as sensitive as urine tests in monitoring of ketosis.

Despite the advantages or disadvantages of urine or milk tests, none of them have excellent sensitivity and specificity compared to the "gold standard" test of blood $\beta \mathrm{OHB}$. Comprehensive comparisons of sensitivity and specificity of different cow-side ketosis tests have been previously reviewed $[1,3]$. Therefore, it is important that a new cow-side test with greater sensitivity and specificity needs to be developed in the future.

Besides lab or strip tests for ketosis, there is also a growing stream of inline milk tests provided by different companies with sensors that can determine milk components automatically including the milk F/P ratio and other milk components. They also provide ketosis test for detection of SCK at an early stage of disease. A study by Jenkins et al. [48] evaluated utilization of the inline milk F/P ratio to diagnose SCK in dairy cows. They used different cut-off values for diagnosis of SCK. The F/P ratio of $>1.33$ resulted in low sensitivity (58\%) and specificity ( $69 \%)$. The best cut-off for this study resulted in a $\mathrm{F} / \mathrm{P}$ ratio of $>1.42$ with $92 \%$ sensitivity and $65 \%$ specificity. These data show that the inline milk $\mathrm{F} / \mathrm{P}$ ratio misses 8 cows with SCK out of 100 and has a high false discovery rate because $68 \%$ of cows with the F/P ratio $>1.42$ are not suffering from SCK.

A meta-analytical study by Tatone et al. [49] compared the accuracy of three tests including Precision $\mathrm{Xtra}{ }^{\circledR}$ for blood $\beta \mathrm{OHB}$, and two semiquantitative tests for milk and urine ketone bodies. The authors concluded that measurement of blood $\beta \mathrm{OHB}$ had the highest overall test accuracy of all available farm tests for detection of hyperketonemia with cut-off point of $1.2-1.4 \mathrm{mmol} / \mathrm{L}$. The authors concluded that further studies are needed to validate automated milk testing technologies and the Ketostix ${ }^{\circledR}$ semiquantitative strips of AcAc measurement in the urine and to increase their sensitivity and specificity.

Two studies assessed the use of automated milk testing technologies using Fourier transform infrared spectroscopy (FTIR) for measurement of Ac [50,51] and 3 other studies evaluated measurement of $\beta$ OHB by FTIR in milk samples from dairy cows [50-52]. FTIR can be incorporated into inline farm systems or provided by service companies. However, the studies had large variation in experimental designs and it is difficult to reach conclusive results. A greater number of standardized studies utilizing automated milk testing technologies are required to fully evaluate the usefulness in HK detection. As an example, the study by van Knegsel et al. [50] used FTIR to measure milk ketone bodies including $\mathrm{Ac}$ and $\beta \mathrm{OHB}$ and milk $\mathrm{F} / \mathrm{P}$ ratio. The authors indicated that measurement of $\mathrm{Ac}$ and $\beta \mathrm{OHB}$ in milk had $80 \%$ sensitivity $(80 \%)$ to detect ketosis compared with $66 \%$ of the milk F/P ratio. However, the 3 FTIR tests ( $\beta \mathrm{OHB}, \mathrm{Ac}$, and F/P ratio) had similar specificity at $71 \%, 70 \%$, and $71 \%$, respectively. They concluded that given the high rate of false positives, the practical application of FTIR tests would not be recommended until a better test is developed.

A study by Jorjong et al. [53] examined the potential of milk fatty acids as a diagnostic tool for ketosis. The authors measured 45 different fatty acids and the ratios of antesio C15:0, antesio C17:0, and the $\mathrm{C} 18: 1$ cis-9-to-C15:0 ratio in the milk of dairy cows. Based on blood, $\beta \mathrm{OHB}$ cows were classified as ketotic $(\beta \mathrm{OHB}>1.2 \mathrm{mmol} / \mathrm{L})$ or normal $(\beta \mathrm{OHB}<1.2 \mathrm{mmol} / \mathrm{L})$. The milk C18:1 cis-9-to-C15:0 ratio was found to be the most discriminating variable for diagnosis of ketosis. Results of this study also showed that $90 \%$ of normal cows had a ratio of C18:1 cis-9-to-C15:0 of 40 or lower, whereas $70 \%$ of ketotic cows had a ratio of C18:1 cis-9-to-C15:0 of greater than 40 . The main issue of the application of this finding is that there is not yet a method for measuring C15:0 in milk.

\subsection{Some Newly Identified Diagnostic Biomarkers}

Besides elevated concentrations of ketone bodies in various body fluids, other variables might also be perturbed during ketosis. Introduction of systems biology approaches and the development of transcriptomics, proteomics, and metabolomics sciences suggest that it is likely that new biomarkers of ketosis can be identified. 
Recently, proteomics analysis of liver, urine, and serum of ketotic cows has been reported. A comparative proteomic assessment of liver proteins and 5 enzymes (i.e., acetyl-coenzyme A acetyltransferase 2, 3-hydroxyacyl-CoA dehydrogenase type-2, elongation factor $\mathrm{Tu}$, alpha-enolase and creatine kinase) revealed that they were differentially expressed in ketotic cows compared with healthy controls [54]. Moreover, urine concentrations of 11 proteins including amyloid precursor protein, apolipoprotein (Apo) C-III, cystatin C, fibrinogen, hepcidin, human neutrophil peptides, osteopontin, VGF (non-acronymic) protein, serum amyloid A (SAA), the C1 inhibitor (C1INH), and transthyretin were decreased in ketotic cows [55]. The same authors reported that serum fibroblast growth factor-21 might be a promising biomarker for detecting ketotic cows [56]. It should be noted that these novel biomarkers have yet to be validated.

\section{Metabolomics: A New Approach to an Old Disease}

\subsection{NMR Spectroscopy and MS-Based Metabolomics}

Metabolomics is a relatively new "omics" science, defined as a comprehensive and fully quantitative analysis of all detectable metabolites (low molecular weight molecules, MW < 1500 Daltons) within a particular biological sample for a complete overview of metabolic status, which provide new insight into pathophysiologic mechanisms in diseases [51]. Metabolomics has been widely-used as a powerful tool for elucidating disease etiologies, developing new biomarkers for detection, and characterization of biological pathways as well as monitoring and predicting complex diseases [57-59].

Nuclear magnetic resonance (NMR) spectroscopy and mass spectrometry (MS) techniques are the most commonly applied analytical platforms for metabolomics studies, although other analytical tools have also been utilized. MS detection is usually integrated with other chemical separation techniques such as gas chromatography (GC), liquid chromatography (LC), or capillary electrophoresis (CE). Utilization of these platforms has helped researchers investigate metabolic profiles employing biological fluids such as blood (serum/plasma), urine, milk, saliva, and cerebrospinal fluid. Metabolomics analysis is generally classified into two experimental strategies (i.e., targeted and non-targeted metabolomics) based on the objective of the investigation [60]. Targeted metabolomics involves quantification of defined groups of biochemically known and chemically characterized metabolites, while non-targeted metabolomics involves the global unbiased qualitative analysis of as many measurable small-molecule metabolites as possible, present within a biological sample including unknown compounds [61,62].

The basic principles and concepts of the two major metabolomics platforms (i.e., NMR and MS) and their individual application in metabolomics research have been described previously [63-65]. The theory of NMR was originally proposed in 1924 by Wolfgang Pauli and NMR spectroscopy was first developed and utilized to measure NMR phenomena in 1946 by researchers at Stanford and M.I.T. universities, in the USA [66,67]. Since then, chemists began to apply the technology to solve chemistry problems such as the characterization of the detailed chemical structure of both large and small molecules. In recent years, NMR technology has been widely used in metabolomics studies for metabolite structural determinations and quantification $[64,68]$.

NMR technology is based on the fact that certain nuclei of atoms (e.g., ${ }^{1} \mathrm{H},{ }^{13} \mathrm{C},{ }^{31} \mathrm{P},{ }^{15} \mathrm{~N},{ }^{19} \mathrm{~F}$, etc.) have magnetic properties (i.e., a spin that generates a small, local magnetic field) that can generate chemical information. For a more comprehensive understanding of the principle behind NMR measurements, please refer to a previously published book chapter by Lane [64]. An NMR spectrum can provide a great deal of information about the chemical structure of pure substances or the chemical composition of complex sample mixtures. Proton $\left({ }^{1} \mathrm{H}\right)$ NMR spectroscopy is most popularly used in metabolomics research, since hydrogen is naturally abundant and is present in almost all organic molecules. One-dimensional (1D) and 2D-NMR approaches are most frequently applied for determining known, unanticipated, or even unknown metabolites. However, the most common, quickest, and easiest NMR experiments in metabolomics studies involve collecting 1D-NMR spectra. 
NMR spectroscopy is recognized as one of the premier approaches for the analyses of multi-component mixtures due to its many advantages including simple sample preparation, essentially universal detection (wide spectrum of multiple classes of metabolites), non-destructive, non-invasive, relatively rapid (>100 samples/day is attainable), cheap (after the initial costs of purchase and installation), and highly reproducible results. The major disadvantages of NMR are high initial cost (over one million dollars) of the instrument and relatively poor sensitivity compared to MS.

As a complementary technique to NMR, a variety of MS approaches have been used to qualitatively and quantitatively measure metabolites from minimal amounts of biological material in numerous metabolomics investigations [63]. The basic principles and applications of MS have been elaborated in many excellent books and review articles [63,69]. Briefly, the first step in the MS analysis of compounds is the generation of gas-phase ions of the molecule of interest (i.e., charged molecules) by an ionization source [e.g., electron ionization (EI), chemical ionization (CI), electrospray ionization (ESI), and matrix assisted laser desorption (MALDI)]. After that, gas-phase ions need to be separated according to their mass-to-charge $(\mathrm{m} / \mathrm{z})$ ratio and detected by a mass analyzer. As there are different ionization sources, several types of mass analyzers are available such as magnetic sector analyzers (MSA), quadrupole analyzers (Q), time-of-flight analyzers (TOF), Fourier-transform ion cyclotron resonance (FT-ICR) analyzers as well as ion trap, orbitrap, and triple quad [69]. Each mass analyzer has its advantages and disadvantages. All mass analyzers apply dynamic or static magnetic and electric fields that can be used alone or combined. Tandem MS (MS/MS) even ${ }^{*}$ MS approaches are more powerful (e.g., higher specificity) and can be used to validate the identity of unknown molecules.

Mass spectrometry is commonly used in combination with prior separation modalities such as GC, LC, and CE to generate hyphenated GC-MS, LC-MS, and CE-MS analysis platforms in metabolomics studies. Direct injection (DI) of serum and urine samples into tandem MS without prior chromatographic separation has also been reported [63,70-72]. In comparison with NMR spectroscopy, the major advantage of MS is the higher selectivity and sensitivity, as mass spectrometers can measure analytes routinely in the femtomolar to attomolar range. One of the major weaknesses of MS techniques in metabolomics is that sample preparation steps such as extraction and derivatization are often required. This procedure can cause metabolite losses and specific metabolite classes may be ignored or discriminated.

In MS-based metabolomics, GC-MS, DI-MS/MS, and LC-MS/MS are the most frequently used platforms. Specifically, GC-MS offers structural information, high throughput, reasonable quantitative precision, relatively high reproducibility and resolution (sensitivity is at least 2 orders of magnitude higher than NMR). However, one limitation of GC-MS is its inability to study metabolites that are not volatile and thermally stable. The greatest advantage of DI-MS/MS is that ideally no metabolites are lost during the sample preparation. However, samples with high-salt or high-protein content can cause ion suppression and adduct formation in the electrospray process, poor chromatographic metabolite separation and degradation of column performance $[63,73]$. The main advantage of LC chromatographic separation-based MS for metabolomic studies is its flexibility. Different combinations of columns and mobile phases make it possible to tailor separations to the compounds of interest.

\subsection{Metabolomic Databases and Bioinformatics Tools for Metabolomics Data Analyses and Interpretation}

Like other "omics" technologies, metabolomics deals with very large datasets. Besides recent innovations in instrumentation, bioinformatics software tools and metabolomic databases are vital for the unbiased, high-throughput, and comprehensive analysis of metabolites. In metabolomics studies, both NMR and MS data are composed of thousands of signals derived from the many hundreds of small molecules. Analysis of such complex data is extremely challenging and time-consuming. In parallel with the development of analytical techniques, various metabolomic databases and computational tools have been developed by researchers in metabolomics.

The Human Metabolome Database (HMDB, http://www.hmdb.ca) is currently the world's most complete and comprehensive database covering most known human metabolites [74-76]. The most 
recent release of HMDB (version 3.6) has been significantly enhanced and expanded over previous versions. Specifically, the number of annotated metabolite entries has grown from 6500 to 41,993 , which include both water-soluble and lipid-soluble metabolites as well as metabolites that are either abundant $(>1 \mu \mathrm{M})$ or relatively rare $(<1 \mathrm{nM})$.

The Bovine Metabolome Database (BMDB) (http://www.cowmetdb.ca/cgi-bin/browse.cgi) is another specific database for dairy cows and beef cattle, which is still in the development process, and is the result of a collaboration between Drs. Ametaj and Wishart at the University of Alberta, Canada. The goal of BMDB is to establish a comprehensive, freely available electronic database of all the detectable metabolites in dairy and beef cattle. The information contains literature and experimentally derived information on bovine serum, bovine urine, bovine milk, bovine ruminal fluid, and bovine meat. Furthermore, the BMDB links metabolites to a MetaboCard that contains specific information acquired from the literature and other databases such as tissue location, biofluid location, NMR, and MS spectra, average concentrations, and associated metabolic pathways (e.g., KEGG pathways) and metabolic enzymes. In the following link, the metabolite glycine (http://www.cowmetdb.ca/cgibin/show_metabolite.cgi?METABOCARD=BMDB00123) has been taken as an example to illustrate the type of information that is available.

Bioinformatic tools, especially software for improved automation have been widely recognized as the bottleneck in metabolomics research. In the past decade, a number of efforts have been made to accelerate or automate compound identification and/or quantification in NMR spectroscopy, GC-MS, and LC-MS. Both raw NMR and MS data require extensive data pre-processing. Major progress has been made in the past decade such that the ability to measure the peaks in global metabolomics datasets has now become routine with the introduction of metabolomic software. The most widely used metabolomic software are MetaboAnalyst and SIMCA-P (www.umetrics.com) [77,78]. MetaboAnalyst is freely available over the web and allows users to upload data, perform data processing, and browse results within a web-based interface. Please refer to Xia et al. $[77,78]$ for more detailed information on the MetaboAnalyst web server.

\subsection{Application of Metabolomics in Studying Ketosis}

Metabolomics has been employed as one of the most powerful approaches in identifying diagnostic biomarkers for the progression of various metabolic diseases or the evaluation of the health status in dairy cows. It is a powerful technique that enables comprehensive identification and quantification of metabolites in an easily accessible biofluid like blood, urine, and milk. This enables discovery of predictive or diagnostic biomarkers in order to distinguish between diseased and non-diseased status [79]. However, very few studies have used more than one analytical technique in metabolomics research in dairy cows. Most metabolomics investigations conducted on dairy cows usually have utilized only one platform (either NMR or MS). Blood (i.e., serum or plasma), urine, rumen fluid, and milk are the most commonly used body-fluids in metabolomics studies by dairy science researchers in biomarker studies and in understanding the etiology of periparturient disease in dairy cows. All of the four body fluids contain hundreds to thousands of detectable metabolites and can be obtained with minimal invasiveness.

\subsection{Using Blood Metabolomics to Screen and Diagnose Diseases}

Blood (i.e., plasma or serum) contributes to maintaining a normal homeostasis in the body by constant regulatory mechanisms. As a result, metabolic fingerprinting of serum or plasma provides a global representation of the immediate metabolic status [80]. Moreover, blood perfuses essentially all living cells in the body and thus it is anticipated to carry vital information about virtually all cell types. In this regard, a number of potential plasma biomarkers of ketosis including several amino acids (AAs), carbohydrates, and fatty acids have been identified by GC-MS, LC-MS, and NMR [81-83].

Metabolomics technologies have been applied by several investigators in the area of periparturient diseases of dairy cows by screening blood samples. GC-MS-based blood metabolomics was applied to 
differentiate metabolic alterations in cows with CK, SCK, and healthy cows [83]. Several metabolic pathways including amino acid metabolism, fatty acid metabolism, gluconeogenesis, glycolysis, and the pentose phosphate pathway were identified to be associated with the development of CK and SCK. Several new plasma biomarkers were also reported to be of importance for the diagnosis and prognosis of ketosis [83]. In another recent study, NMR-based plasma metabolomics was used to distinguish cows with clinical and subclinical ketosis from healthy controls [82]. In this study, Sun et al. [82] demonstrated that 25 metabolites, including acetoacetate, acetone, lactate, glucose, choline, glutamic acid, and glutamine were different among the 3 groups (i.e., Control, CK, and SCK). In another study of ketosis, LC-MS was applied and the authors [81] reported that concentrations of valine (Val), glycine (Gly), glycocholic acid, tetradecenoic acid, and palmitoleic acid increased significantly in cows affected by CK. On the other hand, concentrations of arginine (Arg), aminobutyric acid, leucine (Leu)/isoleucine (Ile), tryptophan (Trp), creatinine, lysine (Lys), norcotinine, and undecanoic acid decreased markedly [81]. In another recent study performed by $\mathrm{Xu}$ et al. [84], different metabolic profiles were determined for type I ketosis and type II ketosis using ${ }^{1} \mathrm{H}-\mathrm{NMR}$ and multivariate analyses. When compared with type II ketosis, cows affected by type I ketosis had greater levels of Ac, acetate, $\beta \mathrm{OHB}$, Ile, Leu, low density lipoproteins (LDL), Val, and VLDL, and lower concentrations of $\alpha$-glucose, $\beta$-glucose, citrate, creatine, formate, glutamine (Gln), glutamate (Glu), Gly, histidine (His), Lys, O-acetyl glycoprotein, phosphocholine (PC), phenylalanine (Phe), and tyrosine (Tyr) [84]. Results from this study seem to indicate the existence of a different pathobiology for type I and type II ketosis in dairy cows.

\subsection{Using Urine Metabolomics to Screen and Diagnose Diseases}

In comparison with other biofluids, urine specimens have advantages because the collection of samples is non-invasive. Furthermore, urine has relatively low levels of large molecules (e.g., proteins or lipids), and high levels of low molecular weight compounds (i.e., metabolites), minimizing the time for sample preparation and resulting in high quality measurements [80]. There are very few urine-based metabolomics studies that report biomarkers for dairy cow diseases. It has been reported that metabolic fingerprinting of human urine can be used as an effective approach to diagnose various diseases and to monitor an individual's general health status [85]. The same can be done for livestock animals and dairy cattle.

\subsection{Using Milk Metabolomics to Diagnose Diseases}

Several milk-based metabolomics approaches have been used to investigate diseases in dairy cows and to evaluate milk quality. NMR metabolomics analysis of milk in dairy cows revealed that milk glycerophosphocholine (GPC)/PC ratio could be used as a biomarker for the risk of ketosis [86]. In another study, associations between milk metabolites and SCC in bovine milk was studied by NMR-based metabolomics [87]. Results of this study demonstrated that milk concentrations of acetate, BHBA, lactate, butyrate, and Ile were increased, whereas hippurate and fumarate were decreased in milk with high levels of somatic cells. Fluctuations of milk composition during clinical mastitis have been reported as promising diagnostic biomarkers of the disease [88]. Data from this study reported that altered milk metabolites are mainly related to carbohydrate, protein, and lipid pathways. With respects to lipid metabolic pathways, there was an increase in milk levels of arachidonic acid metabolites. Among AAs, Arg metabolites were elevated during mastitis, whereas among carbohydrates, concentrations of galactose metabolites were greater in milk of cows with mastitis caused by E. coli and S. aureus.

${ }^{1} \mathrm{H}-\mathrm{NMR}$ analysis of milk samples has been used to monitor metabolic fluctuation over different lactation stages in dairy cows. It was demonstrated that markers (e.g., Ac, BHBA, and citrate) of energy metabolism were increased during early lactation, then diminished over the first 70 days, before stabilizing, suggesting cows experience energy imbalance at initiation of lactation [86]. In another study conducted by Klein et al. [38], MS- and NMR-based metabolomics was applied to investigate 
changes of metabolic variables in the milk during different lactation stages. The authors demonstrated a strong correlation between biomarkers (i.e., acetone and BHBA) and the metabolic status of individual cows during early lactation.

\section{Proposed Etiopathology of Ketosis in Dairy Cows}

\subsection{Importance of Dairy Cow Management during the Dry-Off Period}

The dry period, an anatomically and physiologically challenging time for the cow, is a vital phase in the lactation cycle of dairy cows [89]. It is a period of metabolic, nutritional, and mammary change and an adjustment that profoundly impacts the health status (i.e., incidence of disease), reproduction, and productivity in the next lactation. During the transition from dry-off to early lactation, rumen papillae and microflora must adapt to the newly introduced high concentrate diet. Moreover, the mammary gland undergoes drastic gross and cellular changes at both milk cessation at the beginning of the dry-off and initiation of milking after parturition. Immediately following milk cessation, there is a major engorgement of the cisternal spaces, ducts and alveoli of the gland, which might create conditions for exogenous factors to infect the gland [89].

Dairy cows are highly susceptible to udder infections during the dry-off period. Leelahapongsathon et al. [90] demonstrated that the incidence of bovine intra-mammary infections (IMI) during the dry-off period is almost 4-fold greater than during lactation. It is essential to rigorously apply all the drying-off protocols to prevent infections during the dry-off period.

\subsection{Involvement of Chronic Systemic Inflammatory Insult in Susceptibility to Ketosis}

Several epidemiological studies have shown an association between ketosis and increased susceptibility to infectious diseases like mastitis and metritis [91]. Ametaj et al. [92] suggested that there might be a role of immune factors that trigger systemic inflammation during the transition period in the pathobiology of metabolic disorders. For example, transition dairy cows with fatty liver (a concurrent disease with type II ketosis) were found to have greater concentrations of two acute phase proteins (APPs) (i.e., haptoglobin and serum amyloid A) in the plasma before and after calving, which further supports the assumption that metabolic disorders are associated with low grade chronic inflammation [93].

Three questions need to be answered with regard to potential inflammatory insults in the etiopathology of metabolic disorders, in general and ketosis, in particular: (1) is there an inflammatory response preceding ketosis? (2) what is the source of systemic inflammation? and (3) how does the systemic inflammatory insult contribute to development of ketosis? Indeed, a study conducted by our lab showed that cows with ketosis had overall greater concentrations of serum interleukin (IL)-6, tumor necrosis factor (TNF), serum amyloid A (SAA), and lactate in comparison with the control animals at all or one time point during -8 and -4 weeks prior to calving as well as at parturition [94]. Serum concentrations of IL- 6 and TNF were greater starting at 8 and 4 weeks prior to parturition in cows with ketosis vs. healthy controls. Serum IL-6 and lactate were the strongest discriminators between ketosis cows and healthy ones before the occurrence of ketosis, which might be useful as predictive biomarkers of the disease state. The cause for this state of low-grade chronic inflammation during dry-off is not known at present. There is a need for further research to identify potential causal agents of inflammation during the dry-off period. It is assumed that the subclinical infected mammary gland, during the dry-off period, might be a source of this systemic inflammation. However, this assumption needs to be proved in the near future. Additionally, it might be worth pursuing the hypothesis that ketone bodies released around calving might be a host response to keep inflammation under control. Human research has indicated that $\beta \mathrm{OHB}$ is able to inhibit the NOD-like receptor pyrin-domain containing 3 (NLPR3) inflammasome, which is activated and involved in multiple inflammatory diseases in rodents [95] and other species, including cattle [96]. 
The hypoglycemic hypothesis of ketosis proposes that the major changes in the blood of ketotic cows include increased concentrations of ketone bodies and NEFAs, and decreased levels of glucose, insulin, free and esterified cholesterol, and phospholipids [97]. Moreover, this hypothesis states that alterations of glucose (e.g., gluconeogenesis, glycolysis, and the TCA cycle) and lipid metabolism (e.g., fatty acid $\beta$-oxidation) are associated with the development of ketosis. Therefore, it is of importance to specifically investigate changes of glucose precursors like propionate, gluconeogenic AAs, lactate, and glycerol necessary for gluconeogenesis, intermediates and associated enzymes of the TCA cycle and glycolysis, and triggers for mobilization of fatty acids from adipose tissue in cows with ketosis.

Research conducted by our group reported that cows fed typical early lactation diets trigger a large increase in the concentration of endotoxin [also known as lipopolysaccharide (LPS)], in the rumen fluid. This increase correlated with alterations of plasma metabolites related to lipid and carbohydrate metabolism [98]. The effects of LPS on lipid metabolism also have been previously reported in lactating rats [99]. Feingold et al. [100] showed that LPS induces alterations in lipid metabolism, which subsequently produce hypertriglyceridemia. Elevated concentrations of blood ketones like $\beta \mathrm{OHB}$ might be related to mobilization of lipids and hypertriglyceridemia during a state of endotoxin insult. In support of our assumption are data from Kremer et al. [101] that showed greater blood $\beta \mathrm{OHB}$ and strong correlation between the severity of E. coli mastitis and circulatory $\beta \mathrm{OHB}$. Moreover, infection of the uterine epithelium (i.e., endometritis) postpartum was also shown to be associated with greater concentrations of $\beta \mathrm{OHB}$ in the plasma [102].

It has been reported that ketone bodies, in particular $\beta \mathrm{OHB}$, are able to suppress non-specific immunity by decreasing the efficiency of chemotaxis and phagocytosis in neutrophils of ketotic ruminants [103]. Recently, Youm et al. [95] discovered that ketone body $\beta \mathrm{OHB}$ can regulate innate immune response by blocking NLRP3 inflammasome, which is a newly identified pattern-recognition receptor (PRR) known as the "pyrin domain-containing protein 3" and belongs to the family of nucleotide-binding and oligomerization domain-like receptors (NLRs) $[104,105]$. In addition, $\beta O H B$ can also inhibit processing of IL- $1 \beta$ in response to the toll-like receptor (TLR)- 4 pathogen associated molecular pattern (PAMP) agonist LPS, and the TLR-2 agonist lipoteichoic acid (LTA) [95]. Therefore, elevated ketone bodies during 'ketotic syndrome' might be associated with the activation of the innate immune response and, in particular, $\beta \mathrm{OHB}$ might serve as a metabolite to quell inflammatory responses and alleviate the development of disease. The source of activation of the innate immunity response might be related to intramammary infections during the dry-off period.

\subsection{Protein Mobilization, Lipid Metabolism, and Gluconeogenesis}

Ketosis is a metabolic disease of dairy cows characterized by increased concentrations of ketone bodies in the blood during the transition period, which is attributed to a state of NEB or negative energy balance. Tóthová et al. [106] demonstrated that metabolic changes associated with NEB and lipid metabolism might be related to perturbations in immune functions and protein metabolism. It was estimated that the production of glucose from fermentation of carbohydrates from the diet may fall short of glucose demands by as much as $500 \mathrm{~g} / \mathrm{d}$ during the first week after parturition [16]. Glucogenic amino acids from muscle protein mobilization and glycerol from body fat mobilization likely contribute to making up this shortfall [50,51,107].

Perturbations in lipid metabolism and fatty acid transport in cows with ketosis have been previously determined by gene expression studies. A microarray and qPCR-based transcriptomics study provided evidence for changes in specific lipid catabolism-related genes in the liver of periparturient dairy cows with nutrition-induced ketosis [108]. Fluctuations of metabolites involved in fatty acid metabolism have been reported by several metabolomics studies [77]. For example, Zhang et al. [77] reported that several metabolites (e.g., palmitic acid, heptadecanoic acid, stearic acid, trans-9-octadecenoic acid, myristic acid, and cis-9-hexadecenoic acid from the family of NEFA were elevated in ketotic cows, which confirmed that excessive lipolysis during hypoglycemia leads to ketosis. 
It has also been reported that gluconeogenesis, glycolysis, the TCA cycle, and the pentose phosphate pathway were altered during ketosis [48]. Given the evidence that cows with ketosis experienced fluctuations of intermediates involved in the TCA cycle, glycolysis, and gluconeogenesis, more studies are warranted to complete metabolic profiling of the full picture of energy metabolism to reveal the etiopathology of the disease.

\subsection{Understanding Ketosis at the Level of Systems Biology}

In the past century, most veterinary scientists have been using the reductionist approach to investigate and interpret the etiopathology of periparturient diseases in dairy cows. For example, the blood concentration of $\beta \mathrm{OHB}$ has been suggested and used as the golden standard for diagnosis of ketosis. Is $\beta \mathrm{OHB}$ the only altered variable during the state of ketosis? Can metabolism of $\beta \mathrm{OHB}$ explain all that is happening in cows affected by ketosis? Recent published studies have shown that the number of metabolites perturbed in the blood or milk and metabolic pathways involved during ketosis is quite diverse and complex $[75-77,86]$. The limitations and drawback of the reductionist approach are becoming increasingly apparent and a new approach at the level of systems biology is warranted to better understand the pathobiology of ketosis and develop screening and prognostic biomarkers of disease.

\subsection{Is Ketosis a Host Response to Systemic Inflammation?}

To understand the roles of metabolic status and immune response in the development of ketosis, we compared major indicators of lipid and carbohydrate metabolism and markers for innate immunity activation during the dry-off period (pre-ketotic cows), the week of diagnosis of ketosis (ketotic cows), and the weeks of recovery from ketosis (post-ketotic cows). Results showed that both pre-ketotic and ketotic cows had accumulated pro-inflammatory cytokines [e.g., interleukin-6 (IL-6) and tumor necrosis factor (TNF)] and APPs (e.g., haptoglobin) in the serum when compared to healthy controls, suggesting cows with ketosis experienced a low-grade chronic inflammatory state before the occurrence of disease [94]. Besides $\beta \mathrm{OHB}$, another fuel (i.e., lactate) for energy production was elevated in the serum of both pre-ketotic and ketotic cows, indicating ketosis is accompanied with the enhancement of anaerobic glycolysis. In addition, our study is the first to report that serum concentrations of IL- 6 and lactate were the strongest discriminators between pre-ketotic/ketotic cows and healthy ones, which suggests that those two serum variables might be potential predictive biomarkers for ketosis [94]. Preventing infection of the mammary gland and suppressing the innate immune response and anaerobic glycolysis during the dry-off period might be potential prophylactic targets for managing ketosis in the future.

\subsection{Novel Predictive Serum and Urinary Biomarkers for Ketosis Identified during the Dry-Off Period}

Our team was one of the pioneers using MS- and NMR-based metabolomics to understand the pathobiology of ketosis and other periparturient diseases in dairy cows and to identify novel predictive markers for diseases more than eight weeks before clinical symptoms show up or the confirmation of diagnosis. We performed nested case-control studies by collecting blood and urine samples from healthy controls and diseased cows from the beginning of the dry-off period (i.e., -8 weeks before parturition) until early lactation (i.e., +8 weeks after parturition). Comparisons of metabolic profiles of serum and urine of healthy and diseased cows were performed at five selected time points representing three different stages (i.e.,: (1) Pre-disease stage at -8 and -4 weeks prepartum; (2) Disease stage at the diagnosis week; and (3) Post-disease stage after the recovery at +4 and +8 weeks postpartum) of disease progression. Multiple novel predictive and diagnostic biomarker models in both serum and urine using DI-MS/MS- and LC-MS/MS-based metabolomics and inductively coupled plasma (ICP)-MS analysis of mineral elements were identified. For more details read [109,110].

In a recent targeted metabolomics study, we observed significant changes of several metabolite and lipid species including AAs, acylcarnitines, biogenic amines, glycerophospholipids, 
and sphingolipids in pre-ketotic, ketotic, and post-ketotic cows [109]. To reduce the dimension of dataset and identify biomarkers, multivariate analyses were performed and metabolites were ranked based on their importance in discriminating cows with ketosis versus heathy cows. Specifically, a seven-metabolite-set predictive biomarker model including Lys, lysophosphatidylcholine acyl (lysoPC a) C17:0, lysoPC a C18:0, lysoPC a C16:0, Ile, kynurenine (Kyn), and Leu at -8 weeks, and an eight-metabolite-set predictive biomarker model including Lys, Ile, Leu, Kyn, carnosine, Arg, lysoPC a C17:0, and phosphatidylcholine acylalkyl C44:4 (PC ae C44:4) at -4 weeks were identified for ketosis [109]. Moreover, it was notable that seven serum metabolites (i.e., acetylornithine, decanoyl-l-carnitine, His, Ile, kynurenine, Leu, and Lys) were consistently increased in cows with ketosis throughout the whole experimental period [109]. These findings suggest that ketone bodies are not the only altered metabolites during ketosis. Ketosis is a complex metabolic disease with involvement of disordered amino acid, biogenic amine, and lipid metabolisms.

The ICP-MS study from our team provided new knowledge on alterations of minerals during ketosis [110]. One of the most significant findings was that four predictive serum/urinary mineral biomarker models for ketosis were developed. More specifically, a four-mineral-set predictive serum biomarker model (i.e., aluminum, rubidium, zinc, and chromium) and a three-mineral-set predictive serum biomarker model (i.e., aluminum, manganese, and chromium) for ketosis were identified at -8 and -4 weeks prepartum, respectively. In addition, a five-mineral-set predictive urinary biomarker model (i.e., aluminum, boron, zinc, magnesium, and chromium) and a six-mineral-set predictive urinary biomarker model (i.e., aluminum, phosphorus, calcium, magnesium, sodium, and boron) for ketosis were identified at -8 weeks and -4 weeks prepartum, respectively [110]. Alterations of trace elements and macro-elements in both serum and urine of cows with ketosis indicate that pre-ketotic and ketotic cows had a state of chronic metabolic acidosis, which might further impair bone metabolism and contribute to the progression of ketosis.

Overall, applications of metabolomics studies intend to develop pen-side tests for monitoring or screening cows for susceptibility of ketosis. Metabolomic assays also might find applications in inline automation technologies for diagnosis of various periparturient diseases. Metabolomics assays also might be used in the future to evaluate the prognosis of disease process (i.e., whether the output of the treatment of disease will be positive or negative). Metabolomics also can help in better understanding the etiopathology of a specific disease. We are at the beginning of the application of metabolomics in periparturient diseases of dairy cows. More research will be needed to throw light on the potential causes of periparturient diseases in general and ketosis in particular.

Author Contributions: Conceptualization, B.N.A. and G.Z.; Resources, B.N.A.; Writing-Original Draft Preparation, G.Z.; Writing-Review \& Editing, B.N.A.; Supervision, B.N.A.; Project Administration, B.N.A.; Funding Acquisition, B.N.A. All authors have read and agreed to the published version of the manuscript.

Funding: This research was funded by Genome Alberta and Alberta Livestock and Meat Agency Ltd., grant number ALGP 14.

Conflicts of Interest: The authors declare no conflict of interest.

\section{References}

1. Oetzel, G.R. Monitoring and testing dairy herds for metabolic disease. Vet. Clin. Food Anim. 2004, 20, 651-674. [CrossRef] [PubMed]

2. Tehrani-Sharif, M.; Hadadi, M.; Noughabi, H.H.; Mohammadi, A.; Rostami, F.; Sharifi, H. Bovine subclinical ketosis in dairy herds in Nishaboor, Iran. Comp. Clin Pathol. 2011, 21, 1637-1641. [CrossRef]

3. Oetzel, G.R. Herd-level ketosis-diagnosis and risk factors. American Association of Bovine Practitioners. In Proceedings of the 40th Annual Conference, Vancouver, BC, Canada, 3-6 January 2007.

4. Duffield, T.F. Subclinical ketosis in lactating dairy cattle. Vet. Clin. N. Am. Food Anim. Pract. 2000, 16, 231-253. [CrossRef]

5. Duffield, T.F.; Lissemore, K.D.; McBride, B.W.; Leslie, K.E. Impact of hyperketonemia in early lactation dairy cows on health and production. J. Dairy Sci. 2009, 92, 571-580. [CrossRef] [PubMed] 
6. McArt, J.A.; Nydam, D.V.; Ospina, P.A.; Oetzel, G.R. A field trial on the effect of propylene glycol on milk yield and resolution of ketosis in fresh cows diagnosed with subclinical ketosis. J. Dairy Sci. 2011, 94, 6011-6020. [CrossRef] [PubMed]

7. Ospina, P.A.; Nydam, D.V.; Stokol, T.; Overton, T.R. Evaluation of nonesterified fatty acids and beta-hydroxybutyrate in transition dairy cattle in the northeastern United States: Critical thresholds for prediction of clinical diseases. J. Dairy Sci. 2010, 93, 546-554. [CrossRef]

8. Raboisson, D.; Mounié, M.; Maigné, E. Diseases, reproductive performance, and changes in milk production associated with subclinical ketosis in dairy cows: A meta-analysis and review. J. Dairy Sci. 2014, 97, 7547-7563. [CrossRef]

9. Gordon, J.L. Risk Factors for and Treatment of Ketosis in Lactating Dairy Cows. Ph.D. Thesis, University of Guelph, Guelph, ON, Canada, 2013.

10. Herdt, T.H. Ruminant adaptation to negative energy balance-Influences on the etiology of ketosis and fatty liver. Vet. Clin. N. Am. Food Anim. Pract. 2000, 16, 215-230. [CrossRef]

11. Goff, J.P.; Horst, R.L. Physiological changes at parturition and their relationship to metabolic disorders. J. Dairy Sci. 1997, 80, 1260-1268. [CrossRef]

12. Grummer, R.R. Nutritional and management strategies for the prevention of fatty liver in dairy cattle. Vet. J. 2008, 176, 10-20. [CrossRef]

13. Knowlton, K.F.; Dawson, T.E.; Glenn, B.P.; Huntingto, G.B.; Erdman, R.A. Glucose metabolism and milk yield of cows infused abomasally or ruminally with starch. J. Dairy Sci. 1998, 81, 3248-3258. [CrossRef]

14. Lyle, R.R. Glucose Kinetics and Hepatic Gluconeogenesis in Ketotic and Fasted Steers. Ph.D. Thesis, Iowa State University Ames, Iowa, IA, USA, 1983.

15. Newman, J.C.; Verdin, E. Ketone bodies as signaling metabolites. Trends Endocrinol. Metab. 2014, $25,42-52$. [CrossRef] [PubMed]

16. Drackley, J.K.; Overton, T.R.; Douglas, G.N. 2001. Adaptations of glucose and long-chain fatty acid metabolism in liver of dairy cows during the periparturient period. J. Dairy Sci. 2001, 84, E100-E112. [CrossRef]

17. Hayirli, A. The role of exogenous insulin in the complex of hepatic lipidosis and ketosis associated with insulin resistance phenomenon in postpartum dairy cattle. Vet. Res. Commun. 2006, 30, 749-774. [CrossRef] [PubMed]

18. Suthar, V.S.; Canelas-Raposo, J.; Deniz, A.; Heuwieser, W. Prevalence of subclinical ketosis and relationships with postpartum diseases in European dairy cows. J. Dairy Sci. 2013, 96, 2925-2938. [CrossRef]

19. Gordon, J.L.; LeBlanc, S.J.; Duffield, T.F. Ketosis treatment in lactating dairy cattle. Vet. Clin. N. Am. Food Anim. Pract. 2013, 29, 433-445. [CrossRef]

20. Holtenius, P.; Holtenius, K. New aspects of ketone bodies in energy metabolism of dairy cows: A review. J. Vet. Med. A 1996, 43, 579-587. [CrossRef]

21. Tveit, B.; Lingaas, F.; Svendsen, M.; Sjaastad, O.V. Etiology of acetonemia in Norwegian cattle. 1. Effect of ketogenic silage, season, energy level, and genetic factors. J. Dairy Sci. 1992, 75, 2421-2432. [CrossRef]

22. Duffield, T.F. Minimizing subclinical metabolic diseases in dairy cows. WCDS Adv. Dairy Technol. 2005, $18,43-55$.

23. LeBlanc, S.J.; Leslie, K.; Duffield, T.F. Metabolic predictors of displaced abomasum in dairy cattle. J. Dairy Sci. 2005, 88, 159-170. [CrossRef]

24. Hammon, D.S.; Evjen, I.M.; Dhiman, T.R.; Goff, J.P.; Walters, J.L. Neutrophil function and energy status in Holstein cows with uterine health disorders. Vet. Immunol. Immunopathol. 2006, 113, 21-29. [CrossRef] [PubMed]

25. McArt, J.A.; Nydam, D.V.; Oetzel, G.R. Epidemiology of subclinical ketosis in early lactation dairy cattle. J. Dairy Sci. 2012, 95, 5056-5066. [CrossRef] [PubMed]

26. Dohoo, I.R.; Martin, S.W. Subclinical ketosis: Prevalence and associations with production and disease. Can. J. Comp. Med. 1984, 48, 1-5. [PubMed]

27. Kauppinen, K. Annual milk yield and reproductive performance of ketotic and non-ketotic dairy cows. Zbl. Vet. Med. A 1984, 31, 694-704. [CrossRef] [PubMed]

28. Miettinen, P.V.A. Relationship between milk acetone and milk yield in individual cows. J. Vet. Med. A 1994, 41, 102-109. [CrossRef] [PubMed]

29. Miettinen, P.V.A.; Setala, J.J. Relationships between subclinical ketosis, milk production and fertility in Finnish dairy cattle. Prev. Vet. Med. 1993, 17, 1-8. [CrossRef] 
30. Geishauser, T.; Leslie, K.; Kelton, D.; Duffield, T. Monitoring for subclinical ketosis in dairy herds. Compend. Contin. Educ. Pract. Vet. 2001, 23, S65-S71.

31. Oetzel, G.R. Understanding the Impact of Subclinical Ketosis. In Proceedings of the 24th Florida Ruminant Nutrition Symposium, Gainesville, FL, USA, 3-5 February 2013.

32. Liang, D. Estimating the Economic Losses from Diseases and Extended Days Open with a Farm-level Stochastic Model. Master's Thesis, University of Kentucky, Lexington, KY, USA, 2013.

33. Työppönen, J.; Kauppinen, K. The stability and automatic determination of ketone bodies in blood samples taken in field conditions. Acta Vet. Scand. 1980, 21, 55-61.

34. Kronfeld, D.S.; Raggi, F.; Ramberg, C.F., Jr. Mammary blood flow and ketone metabolism in normal, fasted, and ketotic cows. Am. J. Physiol. 1968, 215, 218-227. [CrossRef]

35. Zhang, Z.; Liu, G.; Wang, H.; Li, X.; Wang, Z. Detection of subclinical ketosis in dairy cows. Pak. Vet. J. 2012, 32, 156-160.

36. Zhang, G.; Hailemariam, D.; Dervishi, E.; Deng, Q.; Goldansaz, S.A.; Dunn, S.M.; Ametaj, B.N. Alterations of innate immunity reactants in transition dairy cows before clinical signs of lameness. Animals 2015, 5, 717-747. [CrossRef] [PubMed]

37. Larsen, T.; Nielsen, N. Fluorometric determination of $\beta$-hydroxybutyrate in milk and blood plasma. J. Dairy Sci. 2005, 88, 2004-2009. [CrossRef]

38. Klein, M.S.; Almstetter, M.F.; Schlamberger, G.; Nürnberger, N.; Dettmer, K.; Oefner, P.J.; Meyer, H.H.D.; Wiedemann, S.; Gronwald, W. Nuclear magnetic resonance and mass spectrometry-based milk metabolomics in dairy cows during early and late lactation. J. Dairy Sci. 2010, 93, 1539-1550. [CrossRef] [PubMed]

39. De Roos, A.P.W.; van den Bijgaart, H.J.; Hørlyk, J.; de Jong, G. 2007. Screening for subclinical ketosis in dairy cattle by Fourier transform infrared spectrometry. J. Dairy Sci. 2007, 90, 1761-1766. [CrossRef]

40. Heuer, C.; Luinge, H.J.; Lutz, E.T.G.; Schukken, Y.H.; van der Maas, J.H.; Wilmink, H.; Noordhuizen, J.P.T.M. Determination of Ac in cow milk by Fourier transform infrared spectroscopy for the detection of subclinical ketosis. J. Dairy Sci. 2001, 84, 575-582. [CrossRef]

41. Duffield, T.F.; Kelton, D.F.; Leslie, K.E.; Lissemore, K.D.; Lumsden, J.H. Use of test day milk fat and milk protein to detect subclinical ketosis in dairy cattle in Ontario. Can. Vet. J. 1997, 38, 713-718.

42. Gantner, V.; Potocnik, K.; Jovanovac, S. Test-day records as a tool for subclinical ketosis detection. Acta Vet. Beogr. 2009, 59, 185-191.

43. Čejna, V.; Chládek, G. The importance of monitoring changes in milk fat to milk protein ratio in Holstein cows during lactation. J. Cent. Eur. Agric. 2005, 6, 539-546.

44. Heuwieser, W.; Falkenberg, U.; Iwersen, M.; Voigtsberger, R.; Padberg, W. Evaluation and use of an automated human $\beta$-hydroxybuturate (BHBA) test for cowside detection of subclinical ketosis in dairy cattle. In Proceedings of the Fortieth Annual Conference, American Association of Bovine Practitioners, Vancouver, BC, Canada, 20-22 September 2007; pp. 253-254.

45. Nielen, M.; Aarts, M.G.A.; Jonkers, A.G.M.; Wensing, T.; Schukken, Y.H. Evaluation of two cowside tests for the detection of subclinical ketosis in dairy cows. Can. Vet. J. 1994, 35, 229-232.

46. Geishauser, T.; Leslie, K.; Tenhag, J.; Bashiri, A. Evaluation of eight cowside ketone tests in milk for detection of subclinical ketosis in dairy cows. J. Dairy Sci. 2000, 83, 296-299. [CrossRef]

47. Osborne, T.M.; Leslie, K.E.; Duffield, T.F.; Petersson, C.S.; TenHag, J.; Okada, Y. Evaluation of Keto-Test in urine and milk for the detection of subclinical ketosis in periparturient Holstein dairy cattle. In Proceedings of the 35th Conference of the American Association of Bovine Practitioners, Rome, GA, USA, 26-28 September 2002; pp. 188-189.

48. Jenkins, N.T.; Peña, G.; Risco, C.; Barbosa, C.C.; Vieira-Neto, A.; Galvão, K.N. Utility of inline milk fat and protein ratio to diagnose subclinical ketosis and to assign propylene glycol treatment in lactating dairy cows. Can. Vet. J. 2015, 56, 850-854. [PubMed]

49. Tatone, E.H.; Gordon, J.L.; Hubbs, J.; LeBlanc, S.J.; DeVries, T.J.; Duffield, T.F. A systematic review and meta-analysis of the diagnostic accuracy of point-of-care tests for the detection of hyperketonemia in dairy cows. Prev. Vet. Med. 2016, 130, 18-32. [CrossRef] [PubMed]

50. Van Knegsel, A.T.M.; Drift, S.G.A.; Horneman, M.; Roos, A.P.W.d.; Kemp, B.; Graat, E.A.M. Short communication: Ketone body concentration in milk determined by Fourier transform infrared spectroscopy: Value for the detection of hyperketonemia in dairy cows. J. Dairy Sci. 2010, 93, 3065-3069. [CrossRef] [PubMed] 
51. Van der Drift, S.G.A.; Jorritsma, R.; Schonewille, J.T.; Knijn, H.M.; Stegeman, J.A. Routine detection of hyperketonemia in dairy cows using Fourier transform infrared spectroscopy analysis of beta-hydroxybutyrate and acetone in milk in combination with test-day information. J. Dairy Sci. 2012, 95, 4886-4898. [CrossRef] [PubMed]

52. Denis-Robichaud, J.; DesCôteaux, L.; Dubuc, J. Accuracy of a new milk strip cow-side test for diagnosis of hyperketonemia. Bovine Pract. Summer 2011, 45, 97-100.

53. Jorjong, S.; van Knegsel, A.T.; Verwaeren, J.; Bruckmaier, R.M.; De Baets, B.; Kemp, B.; Fievez, V. Milk fatty acids as possible biomarkers to diagnose hyperketonemia in early lactation. J. Dairy Sci. 2015, 98, 5211-5221. [CrossRef]

54. Xu, C.; Wang, Z.; Liu, G.; Li, X.; Xie, G.; Xia, C.; Zhang, H.Y. Metabolic characteristic of the liver of dairy cows during ketosis based on comparative proteomics. Asian Aust. J. Anim. Sci. 2008, 21, 1003-1010. [CrossRef]

55. Xu, C.; Shu, S.; Xia, C.; Wang, P.; Sun, Y.; Xu, C.; Li, C. Mass spectral analysis of urine proteomic profiles of dairy cows suffering from clinical ketosis. Vet. Q. 2015, 35, 133-141. [CrossRef]

56. Xu, C.; Xu, Q.; Chen, Y.; Yang, W.; Xia, C.; Yu, H.; Zhu, K.; Shen, T.; Zhang, Z. FGF-21: Promising biomarker for detecting ketosis in dairy cows. Vet. Res. Commun. 2016, 40, 49-54. [CrossRef]

57. Xia, J.; Broadhurst, D.I.; Wilson, M.; Wishart, D.S. Translational biomarker discovery in clinical metabolomics: An introductory tutorial. Metabolomics 2013, 9, 280-299. [CrossRef]

58. Martin, F.P.J.; Collino, S.; Rezzi, S.; Kochhar, S. Metabolomic applications to decipher gut microbial metabolic influence in health and disease. Front. Physiol. 2012, 3, 113. [CrossRef] [PubMed]

59. Nguyen, Q.T.; Merlo, M.E.; Medema, M.H.; Jankevics, A.; Breitling, R.; Takano, E. Metabolomics methods for the synthetic biology of secondary metabolism. FEBS Lett. 2012, 586, 2177-2183. [CrossRef] [PubMed]

60. Dunn, W.B.; Broadhurst, D.I.; Atherton, H.J.; Goodacre, R.; Griffin, J.L. Systems level studies of mammalian metabolomes: The roles of mass spectrometry and nuclear magnetic resonance spectroscopy. Chem. Soc. Rev. 2011, 40, 387-426. [CrossRef] [PubMed]

61. Naz, S.; Vallejo, M.; García, A.; Barbas, C. Method validation strategies involved in non-targeted metabolomics. J. Chromatogr. A. 2014, 1353, 99-105. [CrossRef] [PubMed]

62. Roberts, L.D.; Souza, A.L.; Gerszten, R.E.; Clish, C.B. Targeted Metabolomics. Curr. Protoc. Mol. Biol. 2012, 30, 21-24. [CrossRef]

63. Dettmer, K.; Aronov, P.A.; Hammock, B.D. Mass spectrometry-based metabolomics. Mass Spectrom. Rev. 2007, 26, 51-78. [CrossRef]

64. Lane, A.N. Principles of NMR for Applications in Metabolomics. In The Handbook of Metabolomics, Methods in Pharmacology and Toxicology; Fan, T.W.M., Lane, A.N., Higashi, R.M., Eds.; Springer: Berlin/Heidelberg, Germany, 2012; pp. 127-197.

65. Saleem, F. The Use of Modern Metabolomics and Proteomics to Address the Health Challenges Facing the Canadian Cattle Industry. Ph.D. Thesis, University of Alberta, Edmonton, AB, Canada, 2013.

66. Bloch, F.; Hansen, W.W.; Packard, M. The nuclear induction experiment. Phys. Rev. 1946, 70, 474-485. [CrossRef]

67. Purcell, E.M.; Torrey, H.C.; Pound, R.V. Resonance absorption by nuclear magnetic moments in a solid. Phys. Rev. 1946, 69, 37-38. [CrossRef]

68. Larive, C.K.; Barding, G.A., Jr.; Dinges, M.M. NMR spectroscopy for metabolomics and metabolic profiling. Anal. Chem. 2015, 87, 133-146. [CrossRef]

69. De Hoffmann, E.; Stroobant, V. Mass Spectrometry: Principles and Applications, 3rd ed.; John Wiley \& Sons, Inc.: Hoboken, NJ, USA, 2007; pp. 85-167.

70. Boernsen, K.O.; Gatzek, S.; Imbert, G. Controlled protein precipitation in combination with chip-based nanospray infusion mass spectrometry. An approach for metabolomics profiling of plasma. Anal. Chem. 2005, 77, 7255-7264. [CrossRef]

71. Bouatra, S.; Aziat, F.; Mandal, R.; Guo, A.C.; Wilson, M.R.; Knox, C.; Bjorndahl, T.C.; Krishnamurthy, R.; Saleem, F.; Liu, P.; et al. The human urine metabolome. PLoS ONE 2013, 8, e73076. [CrossRef] [PubMed]

72. Psychogios, N.; Hau, D.D.; Peng, J.; Guo, A.C.; Mandal, R.; Bouatra, S.; Sinelnikov, I.; Krishnamurthy, R.; Eisner, B.; Gautam, N.; et al. The human metabolome. PLoS ONE 2011, 6, e16957. [CrossRef] [PubMed]

73. Pham-Tuan, H.; Kaskavelis, L.; Daykin, C.A.; Janssen, H.G. Method development in high-performance liquid chromatography for high-throughput profiling and metabonomic studies of biofluid samples. J. Chromatogr. B Analyt. Technol. Biomed. Life Sci. 2003, 789, 283-301. [CrossRef] 
74. Wishart, D.S.; Tzur, D.; Knox, C.; Eisner, R.; Guo, A.C.; Young, N.; Cheng, D.; Jewell, K.; Arndt, D.; Sawhney, S.; et al. HMDB: The Human Metabolome Database. Nucleic Acids Res. 2007, 35, D521-D526. [CrossRef]

75. Wishart, D.S.; Knox, C.; Guo, A.C.; Eisner, R.; Young, N.; Gautam, B.; Hau, D.D.; Psychogios, N.; Dong, E.; Bouatra, S.; et al. HMDB: A knowledgebase for the human metabolome. Nucleic Acids Res. 2009, 37, D603-D610. [CrossRef]

76. Wishart, D.S.; Jewison, T.; Guo, A.C.; Wilson, M.; Knox, C.; Liu, Y.; Djoumbou, Y.; Mandal, R.; Aziat, F.; Dong, E.; et al. HMDB 3.0-The Human Metabolome Database in 2013. Nucleic Acids Res. 2013, 41, D801-D807. [CrossRef]

77. Xia, J.; Mandal, R.; Sinelnikov, I.V.; Broadhurst, D.; Wishart, D.S. MetaboAnalyst 2.0-a comprehensive server for metabolomic data analysis. Nucleic Acids Res. 2012, 40, W127-W133. [CrossRef]

78. Xia, J.; Sinelnikov, I.V.; Han, B.; Wishart, D.S. MetaboAnalyst 3.0-making metabolomics more meaningful. Nucleic Acids Res. 2015, 43, W251-W257. [CrossRef]

79. Nicholson, J.K.; Lindon, J.C. Systems biology: Metabonomics. Nature 2008, 455, 1054-1056. [CrossRef]

80. Gowda, G.A.N.; Zhang, S.; Gu, H.; Asiago, V.; Shanaiah, N.; Raftery, D. Metabolomics-based methods for early disease diagnostics: A review. Expert. Rev. Mol. Diagn. 2008, 8, 317-633. [CrossRef]

81. Li, Y.; Xu, C.; Xia, C.; Zhang, H.Y.; Sun, L.W.; Gao, Y. Plasma metabolic profiling of dairy cows affected with clinical ketosis using LC/MS technology. Vet. Q. 2014, 34, 152-158. [CrossRef] [PubMed]

82. Sun, L.W.; Zhang, H.Y.; Wu, L.; Shu, S.; Xia, C.; Xu, C.; Zheng, J.S. ${ }^{1}$ H-Nuclear magnetic resonance-based plasma metabolic profiling of dairy cows with clinical and subclinical ketosis. J. Dairy Sci. 2013, 97, 1552-1562. [CrossRef] [PubMed]

83. Zhang, H.; Wu, L.; Xu, C.; Xia, C.; Sun, L.; Shu, S. Plasma metabolomic profiling of dairy cows affected with ketosis using gas chromatography/mass spectrometry. BMC Vet. Res. 2013, 9, 186. [CrossRef] [PubMed]

84. Xu, C.; Li, Y.; Xia, C.; Zhang, H.Y.; Sun, L.; Xu, C. ${ }^{1} \mathrm{H}$ NMR-based plasma metabolic profiling of dairy cows with Type I and Type II ketosis. Pharm. Anal. Acta 2015, 6, 1000328.

85. Emwas, A.H.; Luchinat, C.; Turano, P.; Tenori, L.; Roy, R.; Salek, R.M.; Ryan, D.; Merzaban, J.S.; Kaddurah-Daouk, R.; Zeri, A.C.; et al. Standardizing the experimental conditions for using urine in NMR-based metabolomic studies with a particular focus on diagnostic studies: A review. Metabolomics 2015, 11, 872-894. [CrossRef]

86. Klein, M.S.; Buttchereit, N.; Miemczyk, S.P.; Immervoll, A.K.; Louis, C.; Wiedemann, S.; Junge, W.; Thaller, G.; Oefner, P.J.; Gronwald, W. NMR metabolomic analysis of dairy cows reveals mlk glycerophosphocholine to phosphocholine ratio as prognostic biomarker for risk of ketosis. J. Proteome Res. 2012, 11, 1373-1381. [CrossRef]

87. Sundekilde, U.K.; Poulsen, N.A.; Larsen, L.B.; Bertram, H.C. Nuclear magnetic resonance metabonomics reveals strong association between milk metabolites and somatic cell count in bovine milk. J. Dairy Sci. 2013, 96, 290-299. [CrossRef]

88. Mansour, R. Proteomics and Metabolomicsstudies on Milk during Bovine Mastitis. Ph.D. Thesis, University of Glasgow, Glasgow, UK, 2012.

89. Dingwell, R.T.; Kelton, D.F.; Leslie, K.E.; Edge, V.L. Deciding to dry-off: Does level of production matter? In Proceedings of the National Mastitis Council Annual Meeting Proceedings, Vancouver, BC, Canada, 11-14 February 2001; pp. 69-79.

90. Leelahapongsathon, K.; Piroon, T.; Chaisri, W.; Suriyasathaporn, W. Factors in dry period associated with intramammary infection and subsequent clinical mastitis in early postpartum cows. Asian-Australas. J. Anim. Sci. 2016, 29, 580-585.

91. Erb, H.N.; GroÈhn, Y.T. Epidemiology of metabolic disorders in the periparturient dairy cows. J. Dairy Sci. 1988, 71, 2557-2571. [CrossRef]

92. Ametaj, B.N.; Bradford, B.J.; Bobe, G.; Nafikov, R.A.; Lu, Y.; Young, J.W.; Beitz, D.C. Strong relationships between mediators of the acute phase response and fatty liver in dairy cows. Can. J. Anim. Sci. 2005, 85, 165-175. [CrossRef]

93. Ametaj, B.N. A new understanding of the causes of fatty liver in dairy cows. Adv. Dairy Technol. 2005, 17, 97-112.

94. Zhang, G.; Hailemariam, D.; Dervishi, E.; Deng, Q.; Goldansaz, S.A.; Dunn, S.M.; Ametaj, B.N. Dairy cows affected by ketosis show alterations in innate immunity and lipid and carbohydrate metabolism during the dry off period and postpartum. Res. Vet. Sci. 2016, 107, 246-256. [CrossRef] [PubMed] 
95. Youm, Y.H.; Nguyen, K.Y.; Grant, R.W.; Goldberg, E.L.; Bodogai, M.; Kim, D.; D’Agostino, D.; Planavsky, N.; Lupfer, C.; Kanneganti, T.D.; et al. The ketone metabolite $\beta$-hydroxybutyrate blocks NLRP3 inflammasome-mediated inflammatory disease. Nat. Med. 2015, 21, 263-269. [CrossRef] [PubMed]

96. Harte, C.; Gorman, A.L.; McCluskey, S.; Carty, M.; Bowie, A.G.; Scott, C.J.; Meade, K.G.; Lavelle, E.C. Alum Activates the Bovine NLRP3 Inflammasome. Front. Immunol. 2017, 8, 1494. [CrossRef] [PubMed]

97. Drackley, J.K. Factors Contributing to Development of Fatty Liver and Ketosis in Lactating Dairy Cows. Ph.D. Thesis, Iowa State University, Ames, IA, USA, 1989.

98. Zebeli, Q.; Dunn, S.M.; Ametaj, B.N. Perturbations of plasma metabolites correlated with the rise of rumen endotoxin in dairy cows fed diets rich in easily degradable carbohydrates. J. Dairy Sci. 2011, 94, 2374-2382. [CrossRef] [PubMed]

99. López-Soriano, F.J.; Williamson, D.H. Acute effects of endotoxin (lipopolysaccharide) on tissue lipid metabolism in the lactating rat. The role of delivery of intestinal glucose. Mol. Cell Biochem. 1994, 141, 113-120. [CrossRef] [PubMed]

100. Feingold, K.R.; Staprans, I.; Memon, R.; AMoser, A.H.; Shigenaga, J.K.; Doerrler, W.; Dinarello, C.A.; Grunfeld, C. Endotoxin rapidly induces changes in lipid metabolism that produce hypertriglyceridemia: Low doses stimulate hepatic triglyceride production while high doses inhibit clearance. J. Lipid Res. 1992, 33, 1765-1776.

101. Kremer, W.D.; Noordhuizen-Stassen, E.N.; Grommers, F.J.; Schukken, Y.H.; Heeringa, R.; Brand, A.; Burvenich, C. Severity of experimental Escherichia coli mastitis in ketonemic and nonketonemic dairy cows. J. Dairy Sci. 1993, 76, 3428-3436. [CrossRef]

102. Yasui, T.; McCann, K.; Gilbert, D.O.; Nydam, D.V.; Overton, T.R. Associations of cytological endometritis with energy metabolism and inflammation during the periparturient period and early lactation in dairy cows. J. Dairy Sci. 2014, 97, 2763-2770. [CrossRef]

103. Sartorelli, P.; Paltrinieri, S.; Agnes, F. Non-specific immunity and ketone bodies. I: In vitro studies on chemotaxis and phagocytosis in ovine neutrophils. J. Vet. Med. A 1999, 46, 613-619. [CrossRef]

104. Inoue, M.; Williams, K.L.; Oliver, T.; Vandenabeele, P.; Rajan, J.V.; Miao, E.A.; Shinohara, M.L. Interferon-beta therapy against EAE is effective only when development of the disease depends on the NLRP3 inflammasome. Sci. Signal. 2012, 5, ra38. [CrossRef] [PubMed]

105. Shao, B.Z.; Xu, Z.Q.; Han, B.Z.; Su, D.F.; Liu, C. NLRP3 inflammasome and its inhibitors: A review. Front. Pharmacol. 2015, 6, 262. [CrossRef] [PubMed]

106. Tóthová, C.; Nagy, O.; Kováč, G. Relationship between some variables of protein profile and indicators of lipomobilization in dairy cows after calving. Archiv. Tierzucht. 2014, 57,1-9. [CrossRef]

107. Overton, T.R.; Drackley, J.K.; Douglas, G.N.; Emmert, L.S.; Clark, J.H. Hepatic gluconeogenesis and whole-body protein metabolism of periparturient dairy cows as affected by source of energy and intake of the prepartum diet. J. Dairy Sci. 1998, 81, 295.

108. Loor, J.J.; Everts, R.E.; Bionaz, M.; Dann, H.M.; Morin, D.E.; Oliveira, R.; Rodriguez-Zas, S.L.; Drackley, J.K.; Lewin, H.A. Nutrition-induced ketosis alters metabolic and signaling gene networks in liver of periparturient dairy cows. Physiol. Genom. 2007, 32, 105-116. [CrossRef]

109. Zhang, G.; Dervishi, E.; Dunn, S.M.; Mandal, R.; Liu, P.; Han, B.; Wishart, D.S.; Ametaj, B.N. Metabotyping reveals distinct metabolic alterations in ketotic cows and identifies early predictive serum biomarkers for the risk of disease. Metabolomics 2017, 13, 43. [CrossRef]

110. Zhang, G.; Dervishi, E.; Mandal, R.; Wishart, D.S.; Ametaj, B.N. Metallotyping of ketotic dairy cows reveals major alterations preceding, associating, and following the disease occurrence. Metabolomics 2017, $13,97$. [CrossRef]

(C) 2020 by the authors. Licensee MDPI, Basel, Switzerland. This article is an open access article distributed under the terms and conditions of the Creative Commons Attribution (CC BY) license (http://creativecommons.org/licenses/by/4.0/). 